\title{
Mitral valve replacement in the presence of severe pulmonary hypertension
}

\author{
T. K. K A UL, W. H. B A IN, J. V. JONES, \\ A.R. LOR IMER, R. M. THOMSON, \\ M.A. TUR NER, and A. ES CAR OUS \\ Departments of Surg:cal and Medical Cardiology and Radiology, Glasgow Royal Infirmary
}

\begin{abstract}
Kaul, T. K., Bain, W. H., Jones, J. V., Lorimer, A. R., Thomson, R. M., Turner, M. A., and Escarous, A. (1976). Thorax, 31, 332-336. Mitral valve replacement in the presence of severe pulmonary hypertension. Thirty patients with severe preoperative pulmonary hypertension (pulmonary artery pressure range $90-165 \mathrm{mmHg}$, mean $118 \mathrm{mmHg}$ ) were reviewed following single mitral valve replacement, with prosthetic valves, within the last 10 years (1964-74). The early and late mortality for this group was no different from that of the total series of mitral valve replacements performed over the same period. Marked postoperative clinical improvement was accompanied by corresponding radiological and electrocardiographic changes. In addition there was a statistically highly significant haemodynamic improvement in the 21 survivors (mean survival time $5 \frac{1}{2}$ years).

At recatheterization the mean pulmonary artery pressure was $41.5 \%$, the mean wedge pressure $46 \cdot 3 \%$, and the transpulmonary gradient (PAm-LAm) $36.1 \%$ of the preoperative values.

It is concluded that gross pulmonary hypertension is not per se a contraindication to mitral valve replacement surgery.
\end{abstract}

The criteria governing the selection of most patients for mitral valve replacement have become standardized over the past two decades, but opinions have differed when the disease is complicated by severe pulmonary hypertension. Early workers regarded the pulmonary vascular changes associated with long-standing mitral valve disease as irreversible (Emanuel, 1963). In general, it has been held that severe pulmonary hypertension was associated with greater operative risk, higher operative mortality, and a poorer long-term prognosis.

However, a significant reduction in the level of pulmonary hypertension in some patients after mitral valve surgery and a more favourable longterm outlook have been reported (Dalen et al., 1967; Zener et al., 1972). Furthermore, Ward and Hancock (1975) suggested that extreme pulmonary hypertension should be regarded as a positive indication for early operation. In their series there was a high mortality in this group, but the prognosis was nonetheless considerably better than the natural history of the diseasio without surgical intervention. In our series in the. last five years, only one of 16 patients with grosis pulmonary hypertension has died during or aftex surgery.

\section{PATIENTS}

Thirty patients (13 men and 17 women, age 23-59) were studied following mitral valve replaces ment (MVR) for isolated mitral valve disease The preoperative pulmonary arterial systolie pressure exceeded $90 \mathrm{mmHg}$ in all (range 90-165 mmHg). The operations were performe over a period of 10 years (1964-74) and the average period of follow-up was five and a halfo years. All the patients had symptomatic mitra $\bar{\Phi}$ valve disease for periods of up to 20 years and $1 \overrightarrow{\mathrm{g}}$ patients had had a previous mitral valvotomy. Th Björk-Shiley tilting disc prosthesis was insertef్ in nine, the Hammersmith disc valve in one, and the Starr-Edwards ball valve prosthesis in $2 £$ 
T A B L E I

SUMMARY OF HAEMODYNAMIC CHANGES IN 21 SURVIVORS

(mean follow-up period $5 \frac{1}{2}$ years)

\begin{tabular}{|c|c|c|c|c|c|c|}
\hline & $\begin{array}{l}\text { Preoperative } \\
\text { Mean }\end{array}$ & \pm SD & $\begin{array}{l}\text { Postoperative } \\
\text { Mean }\end{array}$ & $\pm \mathbf{S D}$ & $\%$ Reduction & P Value \\
\hline Pulmonary arterial systolic pressure & $110 \cdot 5$ & $18 \cdot 9$ & $47 \cdot 5$ & $12 \cdot 4$ & $57 \cdot 2$ & $<0.001$ \\
\hline Pulmonary arterial mean pressure & $74 \cdot 16$ & $18 \cdot 5$ & $30 \cdot 8$ & $5 \cdot 5$ & 58.4 & $<0.001$ \\
\hline $\begin{array}{l}\text { Wedge pressure mean (mmHg) } \\
\text { Transpulmonary arteriovenous }\end{array}$ & $30 \cdot 61$ & $6 \cdot 3$ & $14 \cdot 19$ & 3.9 & $53 \cdot 3$ & $<0.001$ \\
\hline $\begin{array}{c}\text { pressure gradient (PAm-LAm) } \\
\text { Arteriovenous sat. diff. (vol. \%) }\end{array}$ & $\begin{array}{l}43 \cdot 52 \\
63 \cdot 1\end{array}$ & $\begin{array}{l}19 \cdot 7 \\
20 \cdot 0\end{array}$ & $\begin{array}{r}15 \cdot 73 \\
39 \cdot 14\end{array}$ & $\begin{array}{l}5 \cdot 69 \\
16 \cdot 7\end{array}$ & $\begin{array}{l}63 \cdot 85 \\
37 \cdot 93\end{array}$ & $\begin{array}{l}<0.001 \\
<0.001\end{array}$ \\
\hline
\end{tabular}

$\mathrm{SD}=$ standard deviation

patients. Before operation 19 patients were in grade IV, 10 in grade III, and one in grade II of the New York Heart Association classification. After surgery the patients have all been followed up at regular intervals with, at each visit, a full clinical examination, chest radiograph, and electrocardiogram. In the 21 surviving patients, cardiac catheterization has been performed 1-10 years after replacement of the mitral valve.

\section{RESULTS}

There was a progressive fall in hospital mortality over the first five years of mitral valve replacement with maintenance of this improvement in the last five years. In the latter period the hospital mortality for all patients undergoing MVR was $6 \%$.

In the same period 16 patients with severe pulmonary hypertension underwent MVR. None died in hospital and there has been one late death.

The overall survival rate for the group was $50 \%$ as compared with $58 \%$ for the others in the total series (Fig. 1).

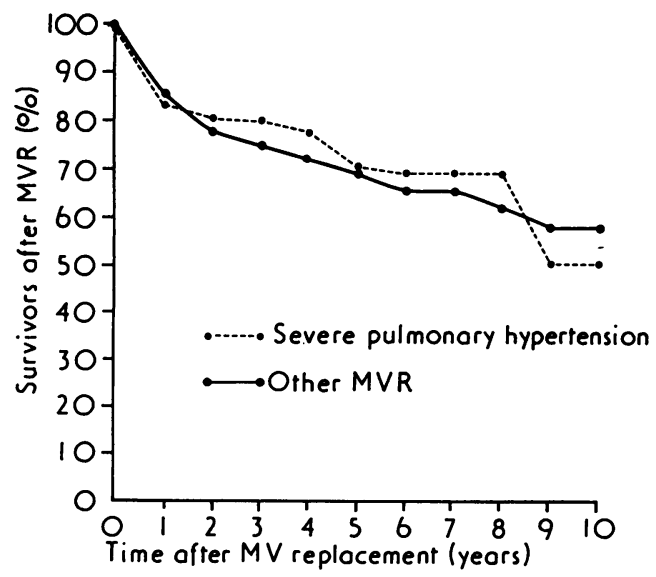

FIG. 1. Overall survival after mitral valve replacement.

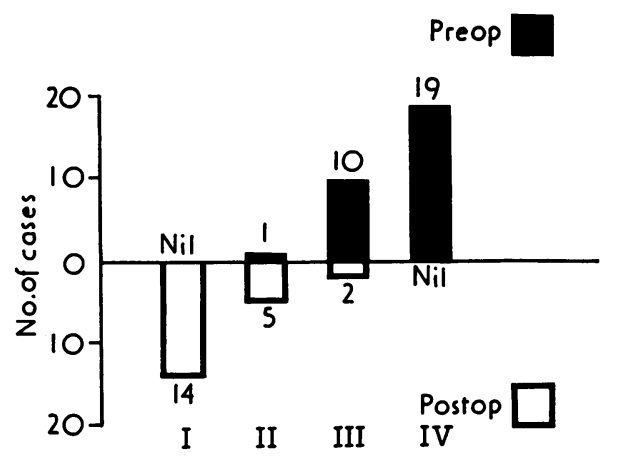

FIG. 2. Clinical gradings.

The findings at recatheterization of the 21 survivors are summarized in Table $I$. These show that there was a highly significant fall in both left atrial and pulmonary pressures after valve replacement in all. The mean pulmonary arterial wedge pressure was $12 \pm 3 \mathrm{mmHg}$ on recatheterization in 17 out of 21 patients, values at the upper limit of normal. The mean pulmonary arterial pressure did not return to normal but fell considerably postoperatively, being $30 \mathrm{mmHg}$ or less in $11(52 \%)$.

The values of the pulmonary arteriovenous pressure gradient (PAm-LAm), which bears a linear relationship to pulmonary vascular resistance $^{1}$ (Wood, 1954) fell significantly in all patients. On the basis of Wood's findings, the estimated values of pulmonary vascular resistance were 10-30 units in 15 patients and 6-10 units in six patients before surgery and fell to less than 6 units in all but two patients.

The changes in clinical gradient are shown in Figure 2. Of the 21 survivors, 14 had improved to

$1 \quad$ PVR $=\frac{\text { PAm - LAm }}{\text { CO }}$

PVR = pulmonary vascular resistance; PAm = mean pulmonary arterial pressure in $\mathrm{mmHg}$; LAm = mean left atrial pressure in $\mathrm{mmHg} ; \mathrm{CO}=$ cardiac output in $1 / \mathrm{min}$ 
grade I when seen 6-12 months after operation. The two patients shown who remained in grade III had paraprosthetic leaks, subsequently requiring resuture of the valve. Both have improved. In all others, early improvement has been satisfactorily maintained.

There was radiological evidence of reduction in heart size, as noted in serial comparable chest radiographs (Table II). The cardiothoracic ratio was reduced in 11 patients $(52 \%)$. This change in transverse diameter was due principally to a reduction in size of the left atrium and right ventricle. The latter was in keeping with electrocardiographic regression of right ventricular hypertrophy in $12(57 \%)$ patients according to standard criteria (Goodwin and Abdin, 1959). There were no rhythm changes (Table III). Three of the four cases with increased transverse cardiac diameter and increased left and right ventricular sizes had some paraprosthetic leak. Dilatation of the main pulmonary artery remained unchanged in $16(76.3 \%)$, regressed in four $(19 \%)$, and apparently increased in one. A reduction in pulmonary venous congestion was noted in 15 $(17 \cdot 4 \%)$ patients, and this improvement has been maintained.

T A B L E I I

RADIOGRAPHIC CHANGES IN 21 PATIENTS WITH SEVERE PULMONARY HYPERTENSION AFTER MITRAL VALVE REPLACEMENT

\begin{tabular}{l|ccc}
\hline \multicolumn{1}{c|}{ Chest Film } & Decrease & Unchanged & Increase \\
\hline C-T ratio & 11 & 6 & 4 \\
MPA & 4 & 16 & 1 \\
RV & 13 & 4 & 4 \\
LV & 4 & 13 & 4 \\
LA & 15 & 5 & 1 \\
Pulmonary venous congestion & 15 & 4 & 2 \\
\hline
\end{tabular}

T A B L E I I I

ELECTROCARDIOGRAPHIC FINDINGS IN 21 PATIENTS ELECTROCARDIOGRAPHIC FINDINGS IN 21 PATIENTS
WITH SEVERE PULMONARY HYPERTENSION BEFORE AND AFTER MITRAL VALVE REPLACEMENT

\begin{tabular}{l|cc}
\hline \multicolumn{1}{c|}{ ECG Finding } & $\begin{array}{c}\text { Before } \\
\text { Operation }\end{array}$ & $\begin{array}{c}\text { After } \\
\text { Operation }\end{array}$ \\
\hline Sinus rhythm & 3 & 3 \\
Atrial fibrillation & 18 & 18 \\
Right ventricular hypertrophy & 21 & 9 \\
\hline
\end{tabular}

DISCUSSION

Patients with severe pulmonary hypertension have been reported to be at two to three times greater risk in the early postoperative period than those with lesser degrees of pulmonary hypertensiom undergoing identical surgical procedures (Starr Herr, and Wood, 1967; Najafi et al., 1969) Furthermore, the long-term prognosis of these patients has been described as poor (Barclay et.al.œ 1972). However, our results indicate that neithe 5 early nor long-term survival after mitral valve replacement is influenced by the severity of the pulmonary hypertension. Nine patients in ouit series died, but seven of these deaths resulte from pre- or postoperative complications, un related to the level of their pulmonary arter pressure, such as air embolism, haemorrhage wound infection, and subacute bacterial endocarditis. Two patients died from respirator $\bar{\varphi}$ failure in which the degree of pulmonary hypertension could have played a part. In the last five years only one patient with gross pulmonar $\Phi$ hypertension has died during or following surgery.

In the 21 patients in whom postoperative haemodynamic measurements were made, the mean pulmonary arterial wedge pressure was normal at rest in 17. The rise in left atrial pressuri: in mitral valve disease has been described as th most significant factor in the development of pulmonary hypertension with consequent vaso? constriction of the pulmonary arterioles (Wood 1958). Some cases are further complicated by organic changes in the pulmonary vasculature. but these changes are moderate (Harris and Heath, 1962) and are probably reversible aftem mitral valve surgery (Ramírez, Grimes, and Abelmann, 1968). Even severe degrees of puB monary hypertension can regress markedly followg ing adequate decompression of the left atrium after closed mitral valvotomy (Werkö et al., 1953 MacKinnon, Wade, and Vickers, 1956; Emanue 1963), open mitral valvotomy (Zener et al., 1972 and mitral replacement (Dalen et al., 1967; Zene et al., 1972). Indeed prosthetic valve replacemen usually allows a better decompression of the lefe atrium than most closed mitral valvotomies (Braunwald et al., 1965) and this is in accord witt the near normal values for left atrial pressure that we obtained in this series at the time of reे catheterization.

We have also observed a marked fall in puto monary arterial pressure and in transpulmonary arteriovenous pressure gradient in these patient The transpulmonary pressure gradient has beeg shown to be related linearly to pulmonary vasculary resistance for a given pulmonary blood flow (Wood, 1954) and to be related to the severity $\frac{\text { ff }}{8}$ 
the pulmonary hypertension. Although pulmonary vascular resistance is regarded as a useful index of severity of pulmonary hypertension, its validity has been questioned (Rudolph and Nadas, 1962) and its interpretation may be difficult (Fritts and Cournand, 1959; Braunwald, Braunwald, and Morrow, 1962). Hamer et al. (1968) suggested that higher values of PVR do not necessarily indicate more severe disease of the pulmonary vasculature. The concept of PVR may be valid for steady flow situations where the resistance varies with the pressure difference across the circuit, but higher values of PVR may be related to low cardiac output as well as to an increase in PAm-LAm (Hollinrake, Baidya, and Yacoub, 1973). Reeve et al. (1966) and Zener et al. (1972) have reported a significant fall in the PVR in the late postoperative period following mitral valve replacement in the presence of extreme pulmonary hypertension. Thus it appears that an early regression of pulmonary hypertension after mitral valve surgery is due to relief of the vasoconstrictive element due to a fall in the left atrial pressure. Eventual regression of pulmonary pressures and pulmonary vascular resistance in the late postoperative period to normal or near normal may be due to reversal of the organic changes in pulmonary arterioles and the medium-sized vessels.

\section{CONCLUSION}

The clinical improvement found in this series has been supported by haemodynamic, electrocardiographic, and radiological changes.

It seems from this study that patients with severe pulmonary hypertension are not at greater risk in the early or late postoperative period than those patients who have a lesser degree of pulmonary hypertension, while in both groups in recent years the mortality has been low. Furthermore, favourable long-term survival after mitral valve replacement has been accompanied by significant clinical improvement in these patients.

We are indebted to Professor T. D. V. Lawrie and other physicians who referred these patients for surgery. Dr. P. W. MacFarlane helped in the analyses of the figures.

\section{REFERENCES}

Barclay, R. S., Reid, J. M., Stevenson, J. G., Welsh, T. M., and McSwan, N. (1972). Long-term followup of mitral valve replacement with StarrEdwards prosthesis. British Heart Journal, 34, 129.
Braunwald, N. S., Braunwald, E., and Morrow, A. G. (1962). Effects of surgical abolition of left to right shunts on the pulmonary vascular dynamics of patients with pulmonary hypertension. Circulation, 26, 1270.

Braunwald, E., Braunwald, N. S., Ross, J., Jr., and Morrow, A. G. (1965). Effects of mitral-valve replacement on the pulmonary vascular dynamics of patients with pulmonary hypertension. New England Journal of Medicine, 273, 509.

Dalen, J. E., Matloff, J. M., Evans, G. L., Hoppin, F. G., Jr., Bhardwaj, P., Harken, D. E., and Dexter, L. (1967). Early reduction of pulmonary vascular resistance after mitral-valve replacement. New England Journal of Medicine, 277, 387.

Emanuel, R. (1963). Valvotomy in mitral stenosis with extreme pulmonary vascular resistance. British Heart Journal, 25, 119.

Fritts, H. W., Jr., and Cournand, A. (1959). Physiological factors regulating pressure, flow and distribution of blood in the pulmonary circulation. In Pulmonary Circulation, An International Symposium, edited by W. R. Adams and I. Veith. Grune and Stratton, New York.

Goodwin, J. F. and Abdin, Z. H. (1959). The cardiogram of congenital and acquired right ventricular hypertrophy. British Heart Journal, 21, 523.

Hamer, J., Boulton, T., Fleming, J., Hayward, G. W., Hill, I. M., Monro, I., Simon, G., and Tubbs, O. S. (1968). Mitral valve replacement: longterm results, with particular reference to changes in pulmonary vascular resistance. Thorax, 23, 1.

Harris, P. and Heath, D. (1962). The Human Pulmonary Circulation, p. 225. Williams and Wilkins, Baltimore: Livingstone, Edinburgh.

Hollinrake, K., Baidya, M., and Yacoub, M. H. (1973). Haemodynamic changes in patients with high pulmonary vascular resistance after mitral valve replacement: comparative study between use of unstinted aortic homograft valves and StarrEdwards prosthesis. British Heart Journal, 35, 1047.

MacKinnon, J., Wade, E. G., and Vickers, C. F. H. (1956). Mitral stenosis with very high pulmonary vascular resistance and atypical features. British Heart Journal, 18, 449.

Najafi, H., Dye, W. S., Javid, H., Hunter, J. A., Ostermiller, W. E., Jr., and Julian, O. C. (1969). Mitral valve replacement. American Journal of Cardiology, 24, 386.

Ramírez, A., Grimes, E. T., and Abelmann, H. W. H. (1968). Regression of pulmonary vascular changes following mitral valvuloplasty. American Journal of Medicine, 45, 975.

Reeve, R., Selzer, A., Popper, R. W., Leeds, R. F., and Gerbode F. (1966). Reversibility of pulmonary hypertension following cardiac surgery. Circulation, 33, supplement 1, 107.

Rudolph, A. M. and Nadas, A. S. (1962). The pulmonary circulation and congenital heart disease: consideration of the role of the pulmonary 
circulation in certain systemic-pulmonary communications. New England Journal of Medicine, 267, 968.

Starr, A., Herr, R. H., and Wood, J. A. (1967). Mitral valve replacement. Journal of Thoracic and Cardiovascular Surgery, 54, 333.

Ward, C. and Hancock, B. W. (1975). Extreme pulmonary hypertension caused by mitral valve disease. British Heart Journal, 37, 74.

Werkö, L., Biörck, G., Crafoord, C., Wulff, H., Krook, H., and Eliasch, H. (1953). Pulmonary circulatory dynamics in mitral stenosis before and after commissurotomy. American Heart Journal, 45, 477.

Wood, P. (1954). An appreciation of mitral stenosis.
Part II. Investigations and results. British Medical Journal, 1, 1113. (1958). Pulmonary hypertension with special reference to the vasoconstrictive factor. British Heart Journal, 20, 557.

Zener, J. C., Hancock, E. W., Shumway, N. E., ando Harrison, D. C. (1972). Regression of extreme? pulmonary hypertension after mitral valve surgery. American Journal of Cardiology, 30 820 .

Requests for reprints to: T. K. Kaul, FRCS, Cardiothoracic Surgical Unit, Royal Infirmary, Glasgow G4 OSF. 